\title{
Genealogia, tRAnSMissão e MEMÓRIA EM BAD GIRL, DE NANCY HuSTON
}

\author{
Genealogy, tRANSmission and memory in BAD GIRL, \\ BY NANCY HUSTON
}

Nubia Tourrucôo Jacques Hanciau

Universidade de Rio Grande

Rio Grande, Brasil

\begin{abstract}
Resumo
À pergunta: "quais são os fatores improváveis que transformam uma criança nascida no Oeste do Canadá, no meio do século XX, em romancista e ensaísta bilíngue e parisiense?", Nancy Huston responde quando conta em Bad girl (2014), sob a forma inédita de uma "autobiografia intra-uterina", o romance de sua vida, fazendo ao mesmo tempo desfilar, em um nível elevado de complexidade e simbolismo, seus anos de juventude, sua família, seus coirmãos literários, suas obsessóes, entre elas notadamente o trauma do abandono que a domina. É a partir desta perspectiva que proponho a leitura de Bad girl baseada na rememoração, na busca genealógica e na transmissão, sem esquecer a música.
\end{abstract}

Palavras-chave: Nancy Huston; Bad girl; romance; genealogia; transmissão.

\begin{abstract}
To the question: "which are the improbable factors that transform a child born in Western Canada, in the middle of the twentieth century, in a Parisian bilingual novelist and essayist?", Nancy Huston answers, in Bad girl (2014), under the unprecedented form of a "intrauterine autobiography", as she tells the story of her life, at the same time parading, with a high level of complexity and symbolism, her youth years, her family, her literary brothers, her obsessions, among them the noticeable abandon trauma that dominates her. It is from this perspective that I propose a reading of Bad girl based on recollection, genealogical search and transmission, without leaving out music.
\end{abstract}

Keywords: Nancy Huston; Bad Girl; novel; genealogy; transmission.

\section{Résumé}

À la question: "quels sont les facteurs improbables qui transforment une enfant née dans l'Ouest du Canada au milieu $\mathrm{du} \mathrm{XX}^{\mathrm{e}}$ siècle en romancière et essayiste bilingue et parisienne?”, Nancy Huston y répond dans Bad girl (2014), sur le mode inédit d'une "autobiographie intra-utérine" en racontant le roman de sa vie, tout en faisant défiler, dans un niveau élévé de complexité et symbolisme, ses années de jeunesse, sa famille, ses confrères littéraires, ses obsessions, dont notamment le trauma de l'abandon qui la domine. C'est à partir de cette perspective que je propose la lecture de Bad girl basée sur la remémoration, la quête généalogique et la transmission, sans oublier la musique.

Mots-clés: Nancy Huston; Bad girl; roman; généalogie; transmission. 
Nesta fase da tua vida não vale mais a pena dizer coisas que vão direto ao teu cérebro. Os intelectuais franceses fizeram isso durante muito tempo, mas isso não te ajuda mais. De agora em diante precisas de coisas que cheguem direto ao teu coração

(Nancy Huston, Bad girl, p. 183). ${ }^{1}$

\section{Preliminares}

Nascida em Calgary em 1953, na província de Alberta, Canadá, Nancy Louise Huston foi abandonada pela mãe na primeira infância, aos seis anos, ocasião em que seus pais se separam. Sua mãe, depois de tantas vezes deixar os filhos aos cuidados de amigos e vizinhos - queria viver experiências de mulher jovem e livre -, finalmente acata o pedido do pai para cessar com o vai-e-vem e não mais ver os filhos, deixando-os em definitivo sob sua guarda. Começa no verão canadense, em julho de 1959, uma vida completamente diferente para a menina, cujo desamparo habitará para sempre seu imaginário: "Oitenta por cento de tua obra literária está contida nessa única tarde, um pouco como a energia nuclear está comprimida em uma bomba atômica. Depois disso uma longa, lenta e silenciosa explosão de palavras, com infinitas recaídas radioativas" (2014: 236).

Náo era tanta a tristeza, mas sim a saudade de dias melhores, da presença da mãe, que verá novamente somente um ano depois, depois disso não a verá mais durante quatro anos; e depois em média uma semana por ano, até a idade adulta. O tema desse abandono, suas repercussóes, predominará em Bad girl (2014), livro-romance-ensaio-fragmentos, no qual, em completa introspecção, Nancy Huston revisita no que se pode chamar de "autobiografia intra-uterina" (quarta capa), várias gerações da história familiar para compreender as marcas que carrega. "No "romance familiar", descrito por Freud e depois magistralmente estudado por Otto Rank, a criança reinventa suas origens. O objetivo essencial dessa atividade é o de "transformar a criação do corpo em uma criação do espirito” (HUSTON, 1995: 66)

O casal de jovens imaturos, personagens de Bad girl, mesmo nos momentos mais banais, quando se alternava uma vida conjugal estável, média, medíocre, previsível, não importa, é percebido pela menina-protagonista como uma aliança de criaturas muito poderosas, que produziam anomalias graves, grandiosas aos seus olhos. Diante dela abrem-se então imensas crateras e os grandes espaços vertiginosos da mitologia: “... é o combate de titãs; a guerra dos

\footnotetext{
${ }^{1}$ As citaçôes de excertos do livro Bad girl - em tradução livre pela autora deste artigo - serão referenciadas somente pelo ano (2014) e número da página. Citaçôes de outras fontes seguem a forma usual.
} 
Centauros contra as amazonas; Hera e Zeus, cujas disputas ressoam através dos céus; a morte de Agamennon por Clitemnestra; o suicídio de Jocasta..." (2014: 231). ${ }^{2}$ Até onde a autora vai, nas origens, para escrever?

Revela-se então o quanto são impressionantes as semelhanças no romance familiar ocidental, sobretudo depois do Século das Luzes, quando o individualismo é promovido à posição de valor absoluto, quando o próprio artista torna-se herói:

[...] se examinarmos qualquer amostragem de biografias de escritores, logo perceberemos que, assim como Édipo, Hamlet ou Antígona, todos viveram na juventude por assim dizer uma anomalia, uma catástrofe, uma perda devastadora. Um pai morreu. Uma mãe morreu. Os dois estão mortos. $\mathrm{Ou}$ separados. Ou radicalmente ausentes. Em outras palavras, o romance familiar desses indivíduos é já e sempre altamente romanesco. Presta-se perfeitamente às especulaçóes, aos fantasmas, às revisóes e às rasuras..., resumindo, à escritura. $\mathrm{O}$ mito nasceu. O herói-escritor poderá beber em sua infância ao infinito, tal qual Homero no fundo mitológico grego, reescrevendo sua história por meio de mil transposiçóes, projeçóes, deslocamentos, símbolos. (2014: 232)

Para contar o que se sucede e desdobra nas "liçóes" - classes de littérature é o subtítulo de Bad girl- que explicam quase tudo, notadamente o pavor do fracasso e o terror do abismo, Nancy Huston mantém uma cronologia clássica no primeiro nível da narrativa, desde a concepção da "menina má" ao seu nascimento, fertilizando os nove meses de gestaçáo com o que conhece do passado de seus pais, somado ao resultado das pesquisas em arquivos, preenchendo as lacunas que restam com farta imaginação. Ela garimpa em sua linhagem o que pode recolher dos seres de onde veio, a rotina de sua própria infância (o que lembra e o que não experimentou diretamente) em uma coleção de acontecimentos quase compulsiva. Em um segundo nível, o tempo do livro, complexo, perturbador, é o tempo do curso desses acontecimentos, misturado ao tempo de sua exposição, que busca o antes, o durante e - por meio de projeçóes arrebatadoras - o depois; enfim, o que constitui um indivíduo, não apenas a história que representa, mas também a que o forjou.

Fica-se dessa forma sabendo que após a partida de Alison, a mãe de Nancy, Alice, sua futura madrasta, a leva de Edmonton para viver durante alguns meses na Alemanha (2014: 202); ${ }^{3}$ depois disso a família instala-se no

\footnotetext{
${ }^{2}$ Aqui são retomados fragmentos de Désirs et réalités (1995), reunião de textos ponte a respeito da extensão da condição humana, em palavras apaixonadas que aproximam o leitor dos romances Cantique des plaines (1993) e de La virevolte (1994).

${ }^{3}$ A viagem à Alemanha, à cidadezinha de Immerath, e a experiência naquele país estão em "La détresse de l'étranger", texto que compóe a coletânea autobiográfica intitulada Nord perdu (subtítulo: suivi de Douze France), publicada pelas ediçôes Actes Sud, Arles (1999: 74-81).
} 
estado de New Hampshire, Estados Unidos, entre outras mudanças incessantes que lhe deixaram para sempre a impressão de estar em lugar nenhum:

Décadas mais tarde as pessoas perguntarão por que a cada romance mudas completamente de universo. A resposta é simples: é o ritmo ao qual te acostumaram, pequena. Arrancar-te todos os anos (e às vezes mais vezes ainda) do que te era familiar. Mudar. Recomeçar do zero. Em outro lugar. O fato de ser a "nova", mais uma vez e mais outra vez - na escola, na igreja, nos cursos de dança, em toda a parte -, será para ti uma aula de literatura potência x! És aquela a quem é preciso tudo explicar, a quem é necessário iniciar nas hierarquias, nos costumes locais, nos jogos de poder. Aprenderás a te colocar no lugar dos outros, a ver o mundo (e a ti mesma) através dos olhos deles. (2014: 158)

Nancy Huston realizou seus estudos universitários em Victoria, na Colúmbia Britânica, depois prosseguiu em Cambridge, no Massachusetts e em Nova Iorque; mas será no outono de 1972, aos quase dezenove anos, que sua vida se transformará: beneficiada por uma bolsa de estudos ingressa na Universidade Sarah Lawrence, ao norte de Nova Iorque. No ano seguinte nova oportunidade, novo deslocamento determina seu destino, agora a capital francesa. Decide instalar-se e permanecer em Paris: “jovem, consagrarás dois anos de tua vida a escrever uma dissertação de mestrado, e depois um livro sobre os palavrôes e as blasfêmias" (2014: 227). ${ }^{4}$ Nessa mesma época ela passa a integrar o movimento de mulheres (MLF) e na esteira do movimento publica artigos em revistas e jornais notadamente Sorcières, Histoires d'Elles e Les Cahiers du Grif. Essa militância feminista se verifica nos textos em circulação na imprensa, em inúmeras entrevistas, nas apresentaçóes públicas, até o presente. ${ }^{5}$ Embora hoje rejeite fortemente a teoria do gênero, em seu entendimento uma negação à realidade, percebe-se ainda em Bad girl um feminismo sutil, onipresente.

"Após vinte anos na escola de Bach-Mozart-Beethoven-SchubertChopin" (2014: 176), a escritora sentiu-se finalmente madura para escrever seu primeiro romance. A estreia na carreira de romancista, em 1981, dá-se com Les Variations Goldberg, acentuando a importância e o lugar que o piano e a música clássica ocupam em sua vida e obra literária.

Ao colocar como título do romance exatamente o mesmo título da obra de J. S. Bach, e ao estruturá-la de forma idêntica à do compositor: uma ária

\footnotetext{
${ }^{4}$ Orientada por Roland Barthes, sob o título Dire interdire: élements de jurologie (1980). Aqui a escritora explora e desvela a ciência dos palavróes (jurons) que inclui blasfêmias, injúrias sexuais e palavras ilegítimas, essas crianças "naturais" que são feitas à língua.

${ }^{5}$ No polêmico ensaio Reflets dans un oeil d'homme (2012), ela discorre a respeito da mulher contemporânea, aderindo à efervescência que ainda vigora no debate fértil sobre os feminismos de todos os gêneros, que hoje conhece novas encarnaçóes literárias e filosóficas, opondo-se ou afiliando-se ao polo em que se transformou a teoria dos gêneros.
} 
inicial, trinta variaçóes e uma ária final, a autora está evidenciando o desejo de experimentação a partir do "modelo" criado por Bach. Além disso, o tema central anunciado na Ária inicial é o da angústia de uma pianista ao executar as Variaçóes Goldberg, o medo de cometer algum deslize e decepcionar seu público. (BERND, 2010: 395)

Durante hora e meia, Liliane Kulainn, a protagonista, reúne amigos para ouvir um recital de cravo. Falam de música e todos têm ligação com a pianista, cada um com direito à sua variação. À medida que as variaçóes se desenvolvem, ouve-se um novo ponto de vista, operando assim o desvio do ethos burguês que mantém os grandes clássicos nos cimos da pureza e da perfeição. Para Liliane, a música cura, dá o ritmo do tempo, fascina, arrancando-nos da fixidez que nos aterroriza. Para Nancy Huston, através do piano é no gosto pelo trabalho paciente, minucioso, obsessivo, mas, sobretudo, ao interpretar excertos de música clássica no piano e no cravo, que ela aprende a exprimir suas próprias emoções na emoção dos outros. As notas dos mestres passam por seu corpo e sua alma em fabulosa catarse: "Marchas militares, arrulhos de pássaros, élans líricos, danças horripilantes, sombrios miasmas em menor, doces harmonias, explosões, lágrimas, gritos...” (2014:176). ${ }^{6}$

Mais tarde, em Plainsong/Cantique des plaines, desde a epígrafe de abertura de Lennon/McCartney ${ }^{7}$ acentua-se a musicalidade. Nancy Huston volta pela primeira vez à língua materna e ao país de origem para retomar a história de quatro geraçóes de imigrantes, os Sterling, que se enraizaram nas planícies albertanas. Depois de ouvir o chamado das planícies em uma canção country, é por meio da protagonista Paula que a autora recupera a história da Alberta sob pretexto de recuperar a de Paddon, adorado avô da protagonista. Revelam-se enfim em Cantique des plaines e notadamente em Pour un patriotisme de l'ambigüité ${ }^{8}$ o ir e vir entre duas subjetividades e duas culturas - a canadense e a francesa -, a valorização de uma escritura das origens, que aponta para um espaço intersticial, transcultural, marcado pela ambivalência e pelo desejo de identificação da escritora com a ambiguidade de sua situação.

Duas décadas depois ela diz: "É a música que unirá os pedaços dissonantes de tua vida. Som, ritmo e melodia serão teus cordóes de segurança,

\footnotetext{
${ }^{6}$ Em 2000, baseada nesse romance, Nancy Huston publica pela Naïve Records o livreto e CD Pérégrinations Goldberg, com Freddy Eichelberger (cravo) e Michel Godard (serpent).

${ }^{7}$ No one you can save that can't be saved. Recusado pelos editores anglófonos, Plainsong foi traduzido pela própria autora para o francês. Ao perceber que a tradução melhora o original, ela passa a utilizar essa técnica de dupla escritura para todos os seus romances, servindo-se do francês exclusivamente para ensaios e artigos. O livro está em processo de tradução pela L\&PM, com o título previsto para $O$ canto das planícies.

${ }^{8}$ Com o subtítulo Notes autour d'un voyage aux sources. Conferência Jarilowsky, proferida na Universidade de Montreal, publicada pelas Ediçôes Fides (1994), traduzida no ano seguinte pela autora deste artigo em $A$ voz da critica canadense no feminino (2001: 215-234).
} 
o cabo que usarás para te rebocar para fora das águas glaciais do pânico e da solidão. As cordas vocais" (2014: 154). Além disso, o piano representava um elemento de decoração sólido e impassível da boa sociedade britânica. Os quatro avós de Dorrit - "a menina má" do título - viam nele um signo exterior de riqueza que proclamava: "Vencemos! Não chafurdaremos mais na lama e no lodo, o estábulo e a imundície, voltamos a ser urbanos em todos os sentidos do termo" (2014: 63).

"O que nos permite continuar?" pergunta-se uma personagem de Göran Tunström em L'oratorio de Noël - "É o som que vai e vem como a água entre as pedras..." (2014: 9). A música atravessa com tanta profundidade as impressôes sensoriais da artista Nancy Huston quanto a ferida do abandono na tenra infância, episódio que denominou de "cataclisma", insistentemente reavivado como uma espécie de expiação, fratura determinante das futuras reações e do seu itinerário. $\mathrm{O}$ poder destruidor dos adultos sobre a criança será tema de premiados romances: La virevolte (1994), em que a personagem Lin liberta-se, oferecendo-se uma saída, uma "viravolta" à maternidade para seguir a carreira de bailarina abandonando as duas filhas pequenas que ficam com o pai; inscrever-se-á duas décadas mais tarde em Danse noire (2013), em que, em introspecção psicológica transgeracional, é explorada a complexidade das origens e da transmissão em três histórias imbricadas em torno da infância difícil de Milo Noirlac, que termina aos cuidados do avô; em L'empreinte de l'ange (1998), em que a força da destruição dos ódios racistas e as marcas dos adultos nas crianças sacrificam o pequeno Emil, apontando mais uma vez para a infância como símbolo da inocência violada.

Apesar da herança fragilizada pela melancolia e tristeza dessas histórias, de girar à volta do mesmo assunto sem encontrar saída, de dar a impressão de impasse, a autora (e suas personagens) mesmo sob o peso do passado demonstra que é possível recriar-se e recrear-se por meio da recorrente articulação entre maternidade e criação literária. ${ }^{9} \mathrm{Na}$ leitura, na música e na literatura, mesmo que não permaneça estranha a passadas tragédias e ao traumatismo, decide ultrapassá-los. Ser feliz será possível por intermédio do delírio ou da arte, que "transforma o lodo em poesia, o sofrimento em êxtase, o patinho feio em cisne" (CYRULNIK, 2005: 3).

\footnotetext{
${ }^{9}$ Em Journal de la création (1990), produzido durante a primeira gestação de Nancy Huston, ela interroga mulheres que desertaram as funçôes de musa, modelo ou esposa maternal para se tornarem poetas. A autora rende-se à evidência: casais escritores famosos - entre eles Scott e Zelda Fitzgerald, Sand e Musset, Sartre e Beauvoir, Plath e Hughes, Virginia e Woolf - colocavam em cena o que acontecia nos bastidores: o conflito entre a arte e a vida que Huston também experimenta, a criação e a procriação, o espírito e o corpo, explorado em paralelo às anedotas biográficas. O livro termina no dia do nascimento de sua filha, Lea, em 1988.
} 
Foi com Instruments des ténèbres ${ }^{10}$ que vieram o sucesso e os prêmios. Esta narrativa entrecruza dois textos distintos produzidos pela mesma instância enunciativa ficcional representada pela narradora Nádia. A ligação de elementos desiguais em sua origem cria a atmosfera ideal para a reconstituição da vida da artista e para a aquisição da consciência de si, à medida que ela se libera de seus sofrimentos e conflitos existenciais. Mas foi sobretudo graças à publicação de Fault lines/Lignes de faille (Marcas de nascença) ${ }^{11}$ que Nancy Huston recebeu um convite para discorrer sobre as teses da "psicologia transgeracional", embora não fosse esse o propósito do best-seller em que as histórias se desdobram de 2004 até 1945, narradas do ponto de vista de uma criança de seis anos, em diferentes estilos para cada capítulo. Desenrola-se no romance um novelo familiar retroativo para contar em primeira pessoa a vida do bisneto Solomon, do pai Randall, da avó Sadie e da bisavó Kristina.

O foco na referida apresentação e que serviu de inspiração para o livro é a história de milhares de crianças originárias da Polônia, da Ucrânia e dos países bálticos, raptadas entre 1942 e 1945 pelos alemães. ${ }^{12}$ Durante o intervalo, uma psiquiatra infantil argumenta que os pesadelos dessas crianças não se deviam tão somente às narrativas, às canções que elas ouviam em sua língua materna, conforme se pensava. Segundo ela: "Existem também marcas arcaicas, pré-verbiais, pré-narrativas, por exemplo, se o bebê dorme com a cabeça apoiada contra as grades do berço é porque busca reencontrar o contato tranquilizador do esterno da mãe" (2014: 150). Intensa vertigem sacudiu nesse momento a escritora Nancy Huston, levando-a de volta à mãe, a antes que seu corpo fosse seu, enquanto ainda estava envolvido pelo dela; e a perguntar-se a respeito das marcas que deixou em seus filhos durante o tempo em que estiveram misturados ao seu próprio corpo. A hereditariedade tem suas leis: nosso cérebro, língua, sensibilidade, personalidade, nossas opiniōes e sentimentos são moldados pelos seres que durante a infância nos falaram e cantaram, ninaram e disciplinaram. "Ora, muitas vezes esses seres viveram coisas atrozes. Mas todos podem passar um traço e dizer: $O$ mundo começa comigo, aqui e agora" (2014: 41-42).

\footnotetext{
${ }^{10}$ Ainda sem tradução para o português, Instruments des ténèbres (1996) foi estudado pela autora deste artigo (2004).

${ }^{11}$ Primeiro romance de Nancy Huston traduzido no Brasil, Marcas de nascença (2007) foi escrito primeiramente em inglês (Fault lines). Best-seller na França (Lignes de faille) recebeu o prêmio Femina e foi finalista no prêmio Goncourt no ano de seu lançamento, entre outras premiaçóes.

${ }^{12} \mathrm{O}$ programa nazista Lebensborns ou fountains of life recolhia crianças de outras naçóes selecionadas com base na cor, tamanho e inteligência, com características físicas semelhantes às da chamada "raça pura”, com o objetivo de redistribuí-las entre as famílias alemãs que pretendiam sua germanização. Cf. Gitta Sereny (2007).
} 
Assim, enraizada em outro lugar há mais de quarenta anos, em nível elevado de complexidade e simbolismo, a escritora perseguirá em Bad girl sua genealogia, enriquecerá sua identidade pessoal e familiar e sua inscrição na história. Ao buscar o sentido cuja "criadora" é ela mesma, verá que é no interior da densa rede dos vínculos familiares que o sentido é forjado; e que é no sistema complexo da família que se encontram os recursos necessários para assegurar a pertença e a autonomia progressiva de cada um dos membros que a compóem. Na perspectiva da rememoraçáo na busca genealógica e da transmissão é que Bad girl, décimo quarto romance de Nancy Huston, será lido a seguir.

\section{Genealogia e transmissão}

Uma família, atrás das "aparências harmoniosas", contém solavancos e rupturas, vazios onde se pode tombar. O escritor encontra nessas lacunas, nos silêncios das vidas, em seu mistério, o espaço para se aventurar. Todo escritor necessita de falhas onde escorregar, abismos, ameaças, enfim. Não é apenas pela evidência e pelo conhecimento que a personalidade e a obra se constroem, mas pelo seu oposto: o que não se sabe, o que se ignora não saber. Se a ignorância faz parte do quadro, há um único molde, apenas uma forma para fabricar o escritor e todo criador: a família.

Para Françoise Payen, não é fácil definir em que consiste o sentimento de pertença a uma família, contudo náo resta dúvida de que um dos elementos importantes é a questão da filiação. Fazer parte de uma família é ocupar lugar na sucessão das geraçóes e na irmandade, reconhecer-se em uma mesma linhagem, receber uma herança.

Mas a herança que se recebe não é unicamente material ou genética. O que se transmite de geração em geraçáo, o que faz o elo e dá o sentimento de pertencer a uma família é muito mais complexo. É da ordem do simbólico, mas pode estar também no registro da transmissão dos fantasmas; $;{ }^{13}$ é forte e impalpável ao mesmo tempo; isso se impóe muitas vezes como uma evidência sobre a qual nada se pode dizer. (PAYEN, 2003: 211)

Nos últimos cinquenta anos as práticas genealógicas desenvolveram-se significativamente, sobretudo na Europa. Seus contextos tradicionais democratizaram-se (Alemanha), popularizaram-se (França), saindo dos compartimentos fechados onde antes se encontravam. Chantal Rodet avança a hipótese de

\footnotetext{
${ }^{13}$ Por fantasmas deve-se entender o conjunto de cenários inconscientes reservados em uma zona pré-consciente ou inconsciente de nosso psiquismo, que nos permite responder aos grandes enigmas de nossa vida (a origem, o amor, a sexualidade, a diferença entre os sexos), questôes que todo ser humano se coloca porque somos seres em busca de sentido. Um dos grandes fantasmas que organizam nossa vida psíquica é aquele que permite responder à questão de nossa origem (PAYEN, 2003: 212).
} 
que não são todas as camadas da sociedade que se interessam pelos seus ancestrais, havendo condições particulares para que venha à tona essa motivação, entre elas a pertença a uma elite e sua prática de legitimação e identificação social, que permitiria aos seus membros, sua família, sair do anonimato conferindo-lhes um nome e, a seguir, conservar o renome adquirido (RODET, 2003: 159). Nessa linha de pensamento a genealogia fabrica e mantém uma predestinação que distingue os indivíduos dos outros membros da sociedade.

As famílias e grupos que tiveram necessidade de ser legitimados em suas funçôes políticas ou sociais e de assim permanecer encontraram entáo na genealogia as formas que produziam os fatos elevados de seus membros e fixavam suas filiaçóes e origens segundo regras estabelecidas. (RODET, 2003: 160)

Em nossos dias a emergência de uma consciência genealógica de si em uma família ou em um grupo é a mesma de um indivíduo ante seu destino e ao de sua descendência. Para Anne Muxel, a transmissão e a memória trabalham na construção e na definição das identidades individuais e coletivas; são elas que desenham os contornos de uma personalidade social, suas idiossincrasias e a singularidade de uma história. "A memória e a transmissão são fabricantes de vínculo, entre os indivíduos, entre as gerações, entre os diferentes tempos históricos que animam a produção de uma sociedade" (MUXEL, 2003: 147). A transmissão atesta um reconhecimento, a memória uma fidelidade; ambas permitem organizar o reencontro com o inesperado, o estrangeiro, o novo, autorizando a triagem e a operação salvadora da seleçáo, condição necessária para a possível inscrição de uma transmissão, que é um ato de projeção em direção a um além, a um outro, e deve buscar seu ponto de apoio, de impulso em uma anterioridade identificada. É preciso partir do conhecido para então reconhecer.

Em âmbito individual, depois de um período de ruptura com a cultura e o lugar de origem, e dos esforços para adaptar-se e assimilar uma nova cultura, ocorre com frequência a necessidade de reatar os elos com as próprias origens, com a história e então preocupar-se com a transmissão. Neste caso, o processo de construção e afirmação da "pertença" familiar e reconstrução do passado torna-se fundamental na construção da identidade pessoal. Ao ilustrar a posição central do processo da memória na transmissão, Margherita $M$. Ciliberto compartilha a ideia de Robert Neuburger e avalia duas formas de representaçôes mnêmicas: a "memória entreposto do tipo computador" que classifica as narrativas, as lembranças, as fotos, as regras, os hábitos de vida, as receitas de cozinha; e processo encarregado principalmente de elaborar o passado, cuja função "é a de assegurar a transmissão, não no sentido de um depósito que passa de mão em mão, mas no de manter a linhagem e a conti- 
nuidade. Assim a memória mantém a permanência do mito e, em consequência, a transmissão da capacidade de transmitir" (CILIBERTO, 2003: 146).

Genealogia, transmissão, em Bad girl

Somos o que somos porque tivemos quem nos criou. Fomos formatados em seus ensinamentos, exemplos e carinhos. Quando os perdemos, cai junto um olhar que nos constituiu. O individualismo dominante gosta de negar a óbvia presença das raízes. Cada um quer pensar-se como engendrado por si mesmo, esquecer o fio de continuidade com os antepassados. (CORSO, 2016: 4)

Se Mario Corso preocupa-se com o individualismo de nossos dias, para Anne Muxel, cabe a cada nova geração negociar sua inscrição na realidade histórica e social com a qual é confrontada, a maneira como vai levar a herança das geraçóes que a precederam, organizar essa herança ou rejeitar (2003: 148). Ciente das armadilhas e das ilusões dos discursos a respeito do "eu”, Nancy Huston usa o "tu" para transmitir sua herança no romance de sua própria vida dirigindo-se ao feto denominado Dorrit, em gestação ao longo das 259 páginas de Bad girl. O bisavô "louco de atar", avô pastor, tia missionária, avó feminista, madrasta alemã, pai brilhante, mas depressivo, mudanças constantes, piano onipresente e a mãe, cujas ambiçôes intelectuais entram em conflito com o papel de dona de casa e mãe, eis os ingredientes que serão recuperados no livro e que revelarão a transformação da criação literária em única maneira de sobreviver.

Foi no mesmo dia da cerimônia de diplomação de Alison que Kenneth, abruptamente anunciou a novidade: “- Nossos filhos sofrem de falta de atenção, diz ele. Olha Dorrit! Ela passa o tempo gemendo e choramingando. Seu nariz escorre. Seus polegares estão cobertos de crostas. A cada noite acorda com pesadelos. Olha para ela! Ela precisa de uma mãe" (2014: 233).

A lesão está inscrita em sua história, gravada em sua memória, como se o patinho feio pensasse: "É preciso bater duas vezes para provocar um traumatismo". O primeiro golpe, no real, provoca a dor do ferimento ou a dilaceraçáo da falta. O segundo, na representaçáo do real, faz surgir o sentimento de ter sido humilhado, abandonado. "E agora, o que vou fazer com isso? Lamentar-me todos os dias, procurar me vingar ou aprender a viver uma outra vida, a dos cisnes?" (CYRULNIK, 2004: 3-4)

Naturalmente Dorrit ignorava aquele ultimato, reconstituído mais tarde, ao longo de décadas, fragmento por fragmento. "Não importa o número de anos que te seráo concedidos, passarás tentando compreender o que aconteceu na primavera de 1959" (2014: 233). Nancy é Dorrit, aquela que escreve e descreve com brio a raiva da mãe, seu desespero de menina e as consequên- 
cias dessa conturbada relação na vida adulta. Ela é toi (tu), que "se" interpelará em todas as idades, e mesmo antes de idade alguma, antes de escrever, antes de ser "eu". "A que escreve é então, também, e às vezes, a que lê. Uma personagem" (2014: 11).

Se pouco se sabe de nosso ser nos primeiros momentos em vida, a história de sua vida será "agarrar-se". "Agarrar-se é a essência, a súmula do teu ser" (2014: 17). Menina má é como Dorrit se sente, insignificante, certa de que os problemas são culpa sua, comprovando-se na narrativa a impossibilidade de separar a própria genealogia da dos ancestrais: a identidade pessoal define-se pela relação com a rede rica de relaçóes familiares e sociais, tanto na dimensão diacrônica quanto na sincrônica (CILIBERTO, 2003: 144).

Era Natal. Kenneth e Alison, por volta dos vinte anos, jovens e belos, vibrantes de hormônios, pais de um menino de dezoito meses - já tendo bebido além da conta, semiconscientes, mais de meia-noite, sem proteção, a farmácia fechada -, foi como "os fluidos do pai inconvenientemente misturaram-se aos da mãe...” (2014: 12). Nesse momento ainda não havia palavras para a indesejada Dorrit descrever o que exatamente aconteceu: "És matéria pura, destituída de palavras e de espírito; entretanto essas células que obstinadamente se dividem e multiplicam já estão dotadas de um programa genético que, ao longo dos próximos nove meses, vai transformá-las, se não houver acidente, em bebê humano" (2014: 15). Janeiro, menos vinte graus! Assim, sem querer, Dorrit foi concebida, sem lugar destinado naquela família.

Ignoras tudo do Canadá e do Natal, ignoras que em oito curtos meses desembarcarás, cabeça primeiro, ou pés primeiro, ou bunda primeiro, bem no centro da civilização ocidental, para viver com um jovem casal protestante, à beira do desentendimento conjugal, na idade pós-industrial, membro de uma família de classe média, descendente, queira ou não, de colonizadores. (2014: 18)

Em Calgary ocorreu a "Anunciação" ao pai do que pode ser tudo, menos uma boa notícia. Kenneth e sua confusão mental. Alison, protótipo da mulher moderna que se obstina em ser "total", sem conseguir, ambos prontos a desempenhar um papel que visivelmente desconhecem.

A genealogia de Dorrit comporta apenas wasps,$^{14}$ enxame de vespas vindas da Irlanda e da Escócia, que atravessaram a Inglaterra, sobrevoaram a França, chegaram à Alemanha por lá permanecendo. O pai de Kenneth era filho de um casal singular: ele lenhador, ela cozinheira, ele surdo-mudo, ela cega. Casados tardiamente, ambos faleceram antes mesmo da adolescência dos dois filhos. Alison, por sua vez, nasceu em 1931, cresceu entre cidadezinhas de Manitoba e da Alberta. Entre seus antepassados uma feiticeira que uivava

${ }^{14}$ White anglo-saxon protestants (brancos anglo-saxôes protestantes). Wasp também significa vespa. 
nas noites de lua cheia e solidão das fazendas da província. Nessa época, dita "bela" em outras partes do mundo, a solidão enlouquecia um número considerável de mulheres que imigraram no oeste canadense. Criadas nas cidades conviviais, coloridas e animadas da Europa, elas náo se acostumavam àquelas paisagens monótonas e vazias, sem o mínimo movimento, muitas vezes cobertas de neve (2014: 55). "Quem sabe herdaste, tu também, Dorrit, um pouco dessa loucura de tua bisavó? (Confessa: em teu foro íntimo, não tiveste sempre um pouco de vontade de uivar olhando a lua?)” (2014: 56).

Quanto ao pai de Alison, ele galgou as escalas da respeitabilidade em sua lenta trajetória de menino que acordava às cinco da manhã para ordenhar as vacas, ao posto de diretor de uma pequena sucursal bancária. A mãe, elegante ex-jogadora de tênis, consagrará o resto de sua vida ao papel de esposa e mãe, escapando por um triz da condição de solteirona. O casal terá duas filhas, depois cessará de procriar, intrigando a respeito da vida sexual dos avós, naquela época ainda mais difícil de imaginar que a dos pais: teriam deixado de fazer amor ou encontraram uma forma de contracepção excepcionalmente eficaz? Nessa retrospectiva a narradora lembra com pertinência que

[em] nenhum lugar no mundo, mesmo entre os Noa-Noa caros a Paul Gauguin, felicidade e desejo foram simples, separados do resto, tributários do presente puro. $\mathrm{O}$ amor não é um assunto privado. Cada um de nós descende e depende de outros membros de nossa espécie [...]. Mesmo se nosso espírito recusa sabê-lo, e mesmo se decidimos não procriar, nosso corpo prolifera dessa descendência e dessa dependência. Não caímos do céu, mas crescemos em uma árvore genealógica. (2014: 48)

Sexo e genealogia mesclam-se e revelam-se inseparáveis na retomada das dificuldades vividas pelos ancestrais, tetravós, bisavós e avós. Como conseguiram apagar os traços da loucura, da cegueira, da surdez, do mutismo, sobretudo, da pobreza, da fome e da angústia que assombraram seu passado? "Entre as histórias que te contarão sobre a vida dos teus avós e antepassados, boa parte se desenrolará sobre fundo de sofrimento, pobreza, atribulações" (2014: 54).

Em curtos capítulos vocativos são expostas sinteticamente essas questóes, entrecruzadas às afinidades que ligam a literatura genealógica à epistemologia das ciências da vida. O "método genealógico" de Zola, um de seus fundadores ao criar a árvore genealógica dos Rougon-Macquart, ${ }^{15}$ vai se atua-

\footnotetext{
${ }^{15}$ História natural e social de uma família sob o Segundo Império, subtítulo dos Rougon-Macquart, em 20 volumes, publicada primeiramente em folhetim em 1870. O método estabelecido por Zola condicionava a escrita dos romances à conclusão dos seguintes passos: apresentar as características dos heróis e a ideia geral do livro (rascunho); determinar o estado civil, os antecedentes hereditários e os traços marcantes das personagens; investigar sobre o meio em que se envolvem, a profissáo que exercem; anotar as leituras, jornais, entrevistas com amigos sobre detalhes para dar autenticidade;
} 
lizando e reativando ao tomar-se conhecimento de como uma família em uma pequena sociedade, um pequeno grupo de seres se comporta, floresce e se desmembra em dez, vinte indivíduos, profundamente diferentes à primeira vista, mas que a análise demonstra estarem ligados uns aos outros. Múltiplas variantes narrativas intercalam-se nessa "escova a contrapelo da história" para revelar as minúcias e os acasos da origem.

Para Benjamin, romancistas como Zola trabalham o vivo a partir da história, fazendo da memória a própria condição da vida (Leben), da sobrevida (Fortleben), e da vida post-mortem (Überleben). Nancy Huston não é diferente. "Endividada" em relaçáo ao passado, responde ao dever de memória para com os ancestrais esquecidos, demonstrando que só há vida autêntica a partir do momento em que a sobrevida excede a vida; e morte biológica quando uma lembrança se elabora, uma transmissão se estabelece ou um "inesquecível" torna-se possível na e pela escritura.

As liçóes de vida que Dorrit (Nancy) apresenta ao leitor ao dirigir-se ao seu duplo valem por ensinamentos teóricos, embora isso não signifique que a escritora, hoje sexagenária, tenha se tornado professora. Mas quem não gostaria - rica das experiências vividas - de voltar, comunicar-se com aquela que foi na aurora da existência? Dessa maneira, interpelada por "tu" em inédito procedimento, é graças a esse distanciamento de si mesma que a narrativa se torna mais franca, diferente do que seria uma autobiografia clássica, nos parâmetros de Philippe Lejeune: "narrativa retrospectiva em prosa que uma pessoa real faz de sua própria existência, quando focaliza sua história individual, em particular a história de sua personalidade" (2008: 14); ou então enquanto "eixo hipotético de um sistema de gêneros" (ARFUCH, 2010: 37). Tais procedimentos e a autobiografia, na perspectiva de "contar a vida de alguém", podem até convergir com a astúcia do emprego do estilo direto, sem artifícios, com os diversos componentes do espaço autobiográfico, com as diferentes possibilidades de combinação e articulação. Mas o resultado da estratégia empregada em Bad girl aponta para uma nova forma de expressão ou subgênero do autobiográfico, que leva a crer que a escritora dirige-se diretamente ao leitor, sem pretender, contudo, em nenhum momento sucumbir à prestaçáo de contas.

Camille Claudel, Annie Ernaux, Clotilde Vautriel (2014: 22-26), companheiras de estrada de Nancy Huston, vêm ao texto iluminar as obsessóes descritas com minuciosas e doloridas reminiscências do aborto que praticaram. O que sofreram assemelha-se ao vivido por milhares de mulheres, na maioria das vezes sós, o corpo crispado de dor e vergonha, imagens algumas

estabelecer o plano capítulo por capítulo. A partir deste planejamento Zola deixava então a "inspiração fluir". 
delas representadas na série de telas - Sans titre (Sem título) -, expostas pela pintora portuguesa Paula Rego em 1997, ano em que Portugal votaria contra o projeto de lei que legalizava o aborto (2014: 24).

Fiz esses quadros para Portugal, diz Rego, que desde os anos cinquenta vive em Londres. Eu via o segredo, a dor, a vergonha. As mulheres vinham o tempo todo me pedir dinheiro para abortar. Às vezes morriam de septicemia. Ou entâo encalhavam na praia, as tripas de fora, como uma vaca velha inchada. $(2014: 24)^{16}$

Embora Dorrit/Nancy não tenha vivido a mesma dolorosa experiência, ela remete ao seu problema: o de estar viva graças ao aborto fracassado da mãe, cuja mensagem as células de seu corpo registraram: "Deverias estar morta, mereces morrer. Teríamos preferido que estivesses morta" (2014: 30).

Os pensamentos, impulsos e gestos assassinos de uma mulher desesperada agiram sobre teu corpo ainda minúsculo, tal qual agiram em La colonie pénitenciaire de Kafka; as agulhas imprimem sua sentença sobre o corpo do prisioneiro, obrigando-o a aprender a ler, não com os olhos, mas com a pele do dorso. (2014: 29)

Como Samuel Beckett, Nancy Huston carrega a sombra dos torturados, dos mortos, dos natimortos e dos não nascidos, a ponto de, em artigo, recomendar a construção de um monumento à "Abortante desconhecida", mártir da sociedade (2014: 29). ${ }^{17}$ Aos quarenta e três anos ela escreverá Limbes/ Limbo, homenagem ao escritor irlandês, encarnando nesta publicação bilíngue mais uma vez o curto-circuito do nascimento à morte (2014: 100). ${ }^{18}$

As asserçóes revelam as próprias convicçóes da escritora e têm o mérito de fazer refletir a respeito da multiplicidade de temas tratados em outros livros: o feminismo, o lugar da mulher na sociedade, a sedução, a aparência, o corpo, a família, o casal, a filiação, a relação mãe e filha, o incesto, os traumatismos e seus efeitos, o destino, lembrando que as mulheres possuem uma memória genealógica mais vasta e mais bem exercida; elas são capazes de articular sua memória por seis ou sete geraçóes, não apenas em profundidade, mas também em ramificaçóes colaterais; isto significa que elas não constroem "uma árvore genealógica, mas uma floresta" (CILIBERTO, 2003: 142).

\footnotetext{
${ }^{16}$ MCEWAN, John. Paula Rego: Behind the Scenes. Londres/Nova York: Phaidon, 2008: 56 apud HUSTON, Nancy. Bad Girl. Arles: Actes Sud, 2014: 261.

${ }^{17}$ Nancy Huston aproveita para lembrar aqui o número expressivo de mulheres que abortaram no Ocidente ao longo dos tempos, na França notadamente, antes da Lei Veil, de 1975.

${ }^{18}$ Bilíngue como Beckett, como ele Huston também enfrenta constantemente a aporia do entredois idiomas. Em Limbes/Limbo, edição bilíngue, o narrador ao mesmo tempo em que denuncia as ilusôes essenciais, deblatera contra a vida - simples queda, do berço ao túmulo -, reclama da vaidade, do absurdo e da contingência.
} 
Esta última frase de Bad girl (2014: 259) encerra as inclassificáveis "aulas de literatura" apontando de maneira original para a necessidade visceral que tem a autora de contar histórias sobre sua própria vida, cujos fragmentos em seu conjunto compóem um texto brilhante e rouco, cujo ritmo - um galope e paradas, pausas inquietas antes dos mais altos obstáculos - e a língua precisa oferecem uma perscrutação no terreno íntimo, onde se interpretam os dramas, se desenham as marcas, nascem os élans, as pulsaçóes e o olhar que a fizeram escritora. Na narrativa a Dorrit, logo a ela própria, o feminino não cessa de ser questionado em análises do papel da mulher e da mãe na sociedade. Com efeito, todos os romances de Nancy Huston são marcados pelo mesmo olhar penetrante em relação aos acontecimentos familiares e pela abordagem psicanalítica ao enfocar as questôes da mulher. Pode-se contudo afirmar que Bad girl é o romance transgeracional mais pessoal, forte e sensível de sua própria vida. Um livro de amor e reconhecimento à literatura que a salvou do naufrágio do abandono, embora o sentimento que prevaleça seja o de girar à volta a partir da concepçáo da narrativa que atravessa a infância e a adolescência, para chegar à idade adulta e à maturidade, parecendo às vezes não encontrar nenhuma saída, exceto a da leitura e da escritura.

Para a romancista Virginia Woolf, a imobilidade denota a catástrofe; agarrar-se à sintaxe, ao som e à música das palavras era a estratégia que adotava frente ao trauma para elaborar uma concepção do tempo menos linear do que global; já a filósofa Simone Weil reivindicava ao contrário, a imobilidade e a perfeição; "Tu Dorrit, adotarás ante o trauma uma e outra combinação em alternância: Woolf e Weil, música e silêncio, água e pedra" (2014: 192). Para Dorrit/Nancy, o trauma provoca ainda uma "sideraçâo", é algo que não passa, que permanece sempre no presente; nele o tempo se fixa; não recua no passado, não se normaliza para pouco a pouco ser integrado ao ritmo da vida; o trauma "tem uma qualidade imediata, invasora, alucinógena. Sua dor permanece viva, exposta. Ele para o tempo” (2014: 182). O trauma do abandono da mãe, compelindo-a desde muito jovem a dirigir-se a ela por cartas, a desenvolver o hábito da comunicação escrita para preencher a falta, predispóe-na desde cedo a tornar-se "mulher de letras". Entretanto a ausência causou tamanha fissura que talvez a cura jamais seja completa; a prova está no título Bad girl. 
Afirma Basel van der Kolk, psicólogo holandês, e Dorrit/Nancy retoma seu pensamento: as emoçóes, gravadas no disco duro do sistema límbico dos animais e dos humanos, são em sua essência imutáveis; o objetivo da emoção é a moção, o movimento, é nos aproximarmos ou afastarmos uns dos outros; o trauma conduz à perda de motivação, afeta e paralisa. O psicólogo trata ainda de aberrante a noção freudiana segundo a qual falar de seu trauma ajudaria a superá-lo, pois no momento em que ele acontece fecha-se o lobo frontal por onde passa a linguagem. Diz ele que "as coisas do corpo", o teatro, a dança, o ioga são mais eficazes para melhorar o estado de uma vítima de trauma, que fica bloqueada. Benéficas as terapias que ajudam a terminar o movimento de defesa, o bloqueio, para dele emergir (2014: 184).

Aprecia-se sobremaneira a leitura de Bad girl na medida em que nos deparamos com retomadas de livros anteriores nas próprias palavras da autora $\mathrm{e}$ na de outros autores e artistas que questionam seus propósitos evidenciando uma vontade superior de compreensão. O leitor por sua vez também é levado a refletir a respeito dos seus "demônios quotidianos". ${ }^{19}$ "Pode-se descobrir os outros em si mesmo, e perceber que não se é uma substância homogênea, e radicalmente diferente de tudo o que não é si mesmo; eu é um outro. Mas cada um dos outros é também um eu, sujeito como eu" (TODOROV, 2011:3). ${ }^{20}$

Uma das "aulas" ministradas por Nancy Huston ensina a conviver: com outros pontos de vista, com as lembranças, a saudade, e até com essas peças que pregamos em nós mesmos quando negamos a morte. Isso tudo vai ficando mais leve, menos frequente, embora não nos recuperemos de todo; um luto completamente bem resolvido não existe, o que existe é aprender a lidar com a falta dos seres queridos que se foram, mas seguem nos fazendo alteridade, de outra forma, integrando a constelação afetiva em que as ausências não alteram a rota dos astros. Talvez por isso não creiamos em fantasmas, em mortos-vivos; "eles se vão, mas não se vai o que sentimos por eles, e nem a função que exercem em nós” (CORSO, 2016: 4).

Perto dos cinquenta anos, em 2003, acreditando que Nancy estava distante de suas raízes, Beatrice, irmã mais moça de Alison, oferece à sobrinha

\footnotetext{
${ }^{19}$ Démons quotidiens (2011) é dedicado à memória do escritor Romain Gary e do pintor Francisco de Goya. Nasceu das afinidades entre a escritora Nancy Huston (1953) e o pintor Ralph Petty (1952).

${ }^{20}$ Tzvetan Todorov, crítico e historiador, trânsfugo como Nancy Huston, viveu com ela desde 1979. Tiveram dois filhos, Lea e Sacha, e publicaram juntos Le chant du Bocage (2005), com fotografias de Jean-Jacques Cornut, sua primeira colaboração literária. Separados, em 2013 ela torna-se oficialmente companheira do pintor suíço Guy Oberson que denomina le Peintre (o Pintor) e a quem se refere ao longo de Bad girl (p. 46, 48, 178, 202). G. Oberson é autor de uma série de aquarelas intitulada Foetus fabulateurs, em alusão ao título do livro L'espèce fabulatrice (2008), traduzido para A espécie fabuladora (2010): um breve estudo sobre a humanidade. Aqui N. Huston relata sua experiência de ficcionista e pensadora, conduzindo o leitor por uma investigação a respeito da genealogia da espécie humana e revelando como nos tornamos os fabuladores que somos.
} 
dois presentes significativos: uma caixa retangular, tendo sobre a superfície a palavra Quill (pena), dentro duas canetas douradas, com o nome do avô gravado; e uma carta escrita por ele, em julho de 1968, dirigida à avó, sobre ela um post-it azul no qual a tia precisa que seu pai amava as palavras. "Em outros termos Dorrit, tens a quem puxar" (2014: 74).

Ao consultar todos esses bonitos escombros, cartas, fotos e lembranças que contigo flutuam no líquido amniótico, pequena Dorrit, impossível não ser tocado pelo fato de que, nos primeiros anos de tua vida, sáo as mulheres que possuem uma memória genealógica vasta, bem exercida e "te colocarão em contato com a literatura e a música" (2014: 62). Reconstituída a memória, depois de interrogar o papel das mulheres em cada época, como ser mulher, mãe, criadora, a bad girl revela enfim a capacidade de articular sua memória abrangendo um período de várias gerações, não apenas em profundidade, mas também ao longo das ramificaçóes colaterais (CILIBERTO, 2003: 144).

"Mesmo os acontecimentos que mudam a história de pessoas já mortas podem nos emocionar profundamente" (2014: 112). Desta forma, com a alma presa e o coração ancorado nas terras "quase" subtraídas, é que Dorrit revive profundamente o medo de errar na eternidade e no limbo, onde o indesejado bebê, em crescimento no ventre da mãe, teria naufragado não tivesse milagrosamente vivido, "se grudado" como se grudaram os mestres Beckett, Romain Gary, menos mentores do que irmáos, experts em vertigem e semelhantes no combate contra as trevas e contra a imobilidade aterrorizante. $\mathrm{O}$ olhar introspectivo desse embrião, a marca indelével da infância graças às relaçôes complicadas com os pais, à complexa linhagem familiar, são fatores transformados em inspiração às aulas de literatura que se refletirão na própria escrita de Nancy Huston. Muitas vezes os leitores perguntam por que a família é seu tema romanesco predileto. Ela então responde:

Haverá outros? Haverá alguma coisa interessante entre os humanos além do fato de que, por boas ou más razóes, intensificadas por pulsóes animais tão inconscientes quanto irresistíveis, eles copulam, fazem filhos, esforçam-se para lhes dar uma educação melhor do que a que receberam, fracassam, envelhecem e morrem depois de ter visto seus filhos crescerem e partirem, encontrar seus próprios companheiros e construir sua própria família como se fossem refazer novamente o mundo, tudo isso sobre um fundo de ranger de dentes, de atribulaçôes políticas, de conflitos religiosos, de rivalidades fraternas, de cenas de incesto e de violação e de morte e de guerra e de prostituição, ornamentado aqui e ali por um piquenique familiar em uma feira agrícola? Do que mais um romance poderia falar? (2014: 86) 


\section{Referências}

ARFUCH, Leonor. $O$ espaço biográfico: dilemas da subjetividade contemporânea. Trad.: Paloma Vidal. Rio de Janeiro: EdUERJ, 2010.

BENJAMIN, Walter. "Sur le concept d'histoire" (1940). In: Écrits français, Paris: Gallimard, 1991: 438.

BERND, Zilá (org.). Dicionário das mobilidades culturais: percursos americanos. Porto Alegre: Literalis, 2010.

BORGES, Rilton Ferreira. "Émile Zola, a formação de um militante", História e Cultura, São Paulo: Franca, v. 3, n. 1, 2014: 253-275. Disponível em: <http://periodicos.franca.unesp.br/index.php/historiaecultura/article/ view/1197/1103>. Acesso em: 12 maio 2016.

CILIBERTO, Margherita M. "L'Articulation des coordonnées spatio-temporelles dans la recherche généalogique: une revue des recherches anthropologiques en Italie sur la mémoire généalogique”. In: RODET, C. La transmission dans la famille: secrets, fictions et idéaux. Paris: L'Harmattan, 2003: 142.

CORSO, Mário. "Nossos mortos. Zero Hora, 13 maio 2016: 4.

CYRULNIK, Boris. Os patinhos feios. São Paulo: Martins Fontes, 2004.

HUSTON, Nancy. "Por um patriotismo da ambiguidade" (Trad.: Nubia Hanciau). In: HANCIAU, N. CAMPELLO, E. SANTOS, E. (Org.). A voz da crítica canadense no feminino. Rio Grande: Ed. da FURG, 2001: 215-234.

HUSTON, Nancy. Dire et interdire: éléments de jurologie. Paris: Payot, 1980. . Les variations Goldberg. Paris: Seuil, 1981.

- Journal de la création. Paris: Seuil, 1990.

- Cantique des plaines. Arles: Actes Sud, 1993.

. La virevolte. Arles: Actes Sud, 1994.

. Instruments des ténèbres. Arles: Actes Sud, 1994.

. Désirs et réalités. Arles: Actes Sud, 1995.

. Nord perdu suivi de Douze France. Arles: Actes Sud, 1999.

. L'empreinte de l'ange. Arles: Actes Sud, 1998.

. Limbes/Limbo. Arles: Actes Sud, 2000.

. Professeurs de désespoir. Arles: Actes Sud, 2004.

Lignes de faille. Arles: Actes Sud, 2006.

. L'espèce fabulatrice. Arles: Actes Sud, 2008.

. Reflets dans un oeil d'homme. Arles: Actes Sud, 2012.

. Danse noire. Arles: Actes Sud, 2013.

. Bad girl. Classes de littérature. Arles: Actes Sud, 2014.

HUSTON, Nancy (texto); PETTY, Ralph (desenhos). Démons quotidiens. Paris: L'Iconoclaste, 2011.

LEJEUNE, Philippe. O pacto autobiográfico: de Rousseau à internet. (Org.: Jovita Maria Gerheim Noronha. Trad.: Jovita Maria Gerheim Noronha; Maria Inês Guedes) Belo Horizonte: Ed. da UFMG, 2008. 
MUXEL, Anne. “Temps, mémoire, transmission”. In: RODET, C. La transmission dans la famille: secrets, fictions et idéaux. Paris: L'Harmattan, 2003: 147-157.

PAYEN, Françoise. Transmission des fantasmes dans la famille. In: RODET, C. La transmission dans la famille: secrets, fictions et idéaux. Paris: L'Harmattan, 2003. p. 211-217.

RODET, Chantal. La transmission généalogique. In: RODET, Chantal. La transmission dans la famille: secrets, fictions et idéaux. Paris: L’Harmattan, 2003. p. 159-171.

SERENY, Gitta. O trauma alemão: experiências e reflexôes, 1938-2001. Rio de Janeiro: Bertrand Brasil, 2007.

TODOROV, Tzvetan. A conquista da América: a questão do outro. São Paulo: Martins Fontes, 2011.

TROYAT, Henri. Zola. São Paulo: Ed. Página Aberta, 1994.

Nubia Tourrucôo Jacques Hanciau é Doutora em Literatura Comparada pela Universidade Federal do Rio Grande do Sul (2001). Professora Titular, atua hoje no Programa de Pós-Graduação em Letras da FURG, Mestrado e Doutorado em História da Literatura. Foi Presidente da ABECAN - Associação Brasileira de Estudos Canadenses (2004-2006). Foi responsável pela editoração da revista Interfaces Brasil/ Canadá de 2004 a 2011. Representou o Brasil junto à AIÉQ - Associação Internacional de Estudos Quebequenses de 1998 a 2000. Sua tese "A feiticeira no imaginário ficcional das Américas", Prêmio ABECAN Melhor tese em 2003, Prix Savard 2005, está entre os 30 livros notáveis no âmbito dos estudos canadenses, com um dos capítulos publicado na Revista Internacional de Estudos Canadenses (RIÉC), em 2006. E-mail: nubiajh@gmail.com.

Recebido em: 31/05/2016 Aprovado em: 24/06/2016 